\title{
DISTRIBUTION OF SULFATE ION ACROSS SEMI-PERMEABLE MEMBRANES ${ }^{1}$
}

\author{
By ROY C. SWAN, ${ }^{2}$ HOWARD M. FEINSTEIN, AND HARRY MADISSO with THE \\ TECHNICAL ASSISTANCE OF ANGELA PLINKE AND HERMAN SHARMA
}

(From the Department of Physiology, Cornell University Medical College, New York, N. Y.)

(Submitted for publication November 17, 1955 ; accepted February 9, 1956)

The volume of distribution of radiosulfate is assumed by some investigators to be a measure of extracellular fluid volume in the whole body and in tissues $(1,2)$. Radiosulfate is apparently distributed into the same portion of body fluids as are mannitol and thiosulfate (3), but is more suitable in this measurement in that correction need not be made for changing plasma blank as in the case of mannitol, and errors in extrapolation for slow disappearance of radiosulfate from extracellular fluid are less than in the cases of the more rapidly disappearing thiosulfate and mannitol. A disadvantage is that the distribution of the sulfate ion across capillary and cell membranes (with the exception of the erythrocyte membrane in certain species) is not known.

In calculating the volume of distribution of radiosulfate it has been assumed that the concentration of sulfate in the water of plasma is only 90 per cent of that in an ultrafiltrate of plasma $(1,3)$. This ratio of concentrations is derived from a ratio for monovalent ions (4) and the fact that theoretically the ratio of concentrations of a divalent ion across a semipermeable membrane is the square of the ratio for monovalent ions (5). Exclusion of the sulfate ion from erythrocyte water has been claimed $(6,7)$, and has been assumed in the previous calculations of sulfate distribution $(1,3)$. However penetration of rat erythrocytes by this ion has been observed by Sheatz and Wilde (8) within a few minutes of the addition of radiosulfate to plasma, and studies of anion distribution in human erythrocytes by Wilbrandt (9) and in bovine erythrocytes by Schwietzer and Passow (10) indicate that the distribution of the sulfate ion across the erythrocyte membrane approximates that predictable on the basis of Donnan theory.

\footnotetext{
1 Supported by a grant by the American Heart Association.

2 Present address : Physiological Laboratory, Cambridge, England.
}

To approximate the distribution of sulfate across the capillary membrane the distribution of radiosulfate has been measured in the water of human and canine sera and in dialysates separated from these sera by cellophane membranes. The distribution of sulfate across the erythrocyte membrane has been studied in vivo by measuring radiosulfate concentration in whole blood and plasma for several hours after infusing radiosulfate into nephrectomized dogs.

\section{EXPERIMENTAL PROCEDURE}

\section{a) In vitro dialysis of plasma}

Blood was collected in dry syringes from healthy men and women and healthy male and female dogs. After clotting and centrifugation, sera were separated and placed in dialyzing units. Dialyzing units similar to that described by Hastings, Salvesen, Sendroy, and Van Slyke (4) were constructed from material and of dimensions shown in Figure 1. Eight milliliters of serum were exposed through $32 \mathrm{~cm}^{2}$ of cellophane (No. 300 P. T., Du-

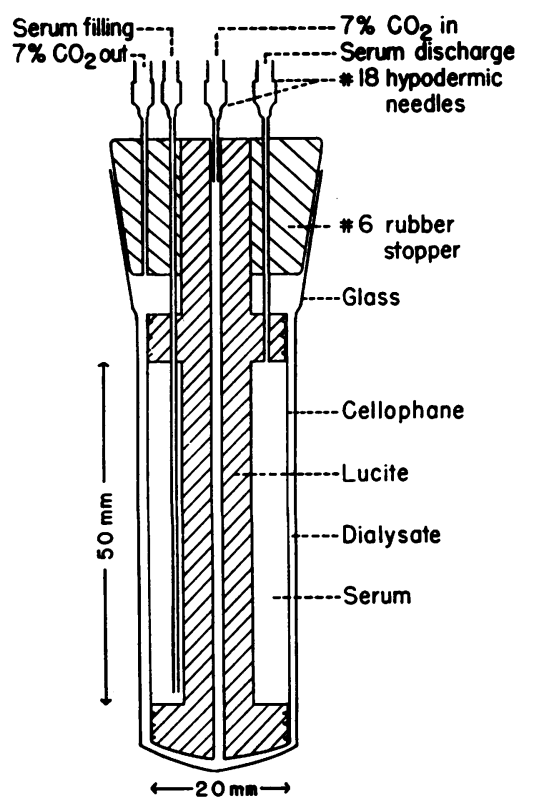

Fig. 1. Cross-Section of Dialyzing Unit 
Pont, three-quarter inch tubing, with glycerine removed by rinsing in water) to nine milliliters of dialysate containing sodium (147 $\mathrm{mM}$ per liter), potassium (6 $\mathrm{mM}$ per liter), bicarbonate ( $32 \mathrm{mM}$ per liter), chloride (119 $\mathrm{mM}$ per liter $)$, sulfate $(1.0 \mathrm{mM}$ per liter $)$ and radiosulfate (approximately 20 microcuries per liter). Hydrogen ion concentration was stabilized and oncotic pressure of plasma proteins opposed by constantly drawing gas containing $\mathrm{CO}_{2}$ at 7 volumes per cent through the dialysate at a pressure of minus $30 \mathrm{~mm}$. $\mathrm{Hg}$. Gas containing $\mathrm{CO}_{2}$ was supplied from a spirometer after mixing gases of known composition. Attainment of equilibrium across the cellophane membrane was facilitated by constantly bubbling gas through the dialysate, by very briefly bubbling the same gas mixture through the serum at half hour intervals and by constantly shaking the unit in a Warburg water bath at $37^{\circ} \mathrm{C}$. for 6 hours. Five such dialyzing units in parallel were used simultaneously.

Following completion of the six-hour equilibration, samples of serum were collected anaerobically for measurement of $\mathrm{pH}$. The remainder of the serum as well as the dialysate then was removed rapidly from the dialyzing unit for measurement of concentrations of serum water, protein, "albumin," and of radiosulfate in serum and dialysate. To check the validity of the experimental procedure concentrations of sodium, potassium and chloride in serum and dialysate were measured for comparison of the calculated concentration ratios of these ions with those established by others (11).

b) In vivo distribution of radiosulfate between plasma and erythrocytes

Healthy male dogs were anesthetized with sodium pentobarbital and nephrectomized bilaterally to diminish

TABLE I

Ratios of concentrations of ions in serum water ( $s$ ) and dialysate $(f)$ at equilibrium

\begin{tabular}{|c|c|c|c|c|c|c|c|c|}
\hline \multirow{2}{*}{$\begin{array}{l}\text { Exp. } \\
\text { No. } \\
\text { Man }\end{array}$} & \multicolumn{4}{|c|}{ Serum } & $\mathrm{No}$ & $K$ & $\mathrm{Cl}$ & $\mathrm{s}^{35} \mathrm{q}_{4}$ \\
\hline & $\begin{array}{c}\mathrm{H}_{2} \mathrm{O} \\
\%\end{array}$ & $\mathrm{pH}$ & $\begin{array}{l}\text { Protein } \\
\text { gm \% }\end{array}$ & $\mathrm{A} / \mathrm{G}$ & \multicolumn{2}{|c|}{$r_{f} / s$} & \multicolumn{2}{|c|}{$r_{s} / f$} \\
\hline 1 & 94.1 & 7.39 & 6.96 & 1.95 & .947 & .923 & .983 & .940 \\
\hline 2 & 93.0 & 7.41 & 7.46 & 201 & .928 & .915 & .972 & .930 \\
\hline 3 & 93.1 & 7.37 & 7.09 & 1.82 & .929 & .931 & 1.019 & .966 \\
\hline 4 & 93.8 & 7.43 & 7.49 & 2.15 & .940 & .956 & 1.009 & .970 \\
\hline 5 & 94.1 & 7.39 & 6.85 & 2.04 & .948 & .959 & .983 & .937 \\
\hline AV. & & & 7.17 & 2.0 & .94 & .94 & .99 & .95 \\
\hline$D O G$ & & & & & & & & \\
\hline 1 & 94.2 & 7.38 & 6.05 & 1.43 & .942 & .942 & .992 & .964 \\
\hline 2 & 95.1 & 7.35 & 5.31 & 1.44 & .949 & 1.010 & .942 & .967 \\
\hline 3 & 93.8 & 7.37 & 6.80 & 1.55 & .941 & .938 & .985 & .928 \\
\hline 4 & 93.9 & 7.37 & 6.08 & 1.58 & .938 & .939 & .986 & .984 \\
\hline 5 & 94.8 & 7.33 & 5.98 & 1.58 & .943 & .965 & .999 & .962 \\
\hline 6 & 93.3 & 7.40 & 6.62 & 1.67 & .934 & .936 & .992 & .930 \\
\hline 7 & 94.4 & 7.38 & 6.32 & 1.79 & .943 & .925 & .987 & .957 \\
\hline 8 & 93.0 & 7.35 & 6.18 & 1.29 & .938 & .958 & .986 & .953 \\
\hline 9 & 94.2 & 7.41 & 6.29 & 1.42 & .935 & .906 & .989 & .983 \\
\hline 10 & 94.4 & 7.38 & 6.05 & 1.44 & .947 & .910 & .977 & .954 \\
\hline AV. & & & 6.17 & 1.5 & .94 & .94 & .98 & .96 \\
\hline
\end{tabular}

TABLE II

Ratios of concentrations of radiosulfate in erythrocyte water ( $c$ ) and plasma water ( $p$ ) at various times after infusion of radiosulfate into nephrectomized dogs

\begin{tabular}{|c|c|c|c|}
\hline $\begin{array}{c}\text { Elapsed } \\
\text { Time } \\
\text { hours }\end{array}$ & \multicolumn{3}{|c|}{$r_{\text {C/p }}$} \\
\cline { 2 - 4 } & Exp. 1 & Exp 2 & Exp. 3 \\
\hline 2 & .43 & .44 & .36 \\
3 & .41 & & \\
4 & .45 & .40 & .37 \\
6 & & & \\
& & .39 & .40 \\
8 & & & \\
\hline Av. & .43 & .40 & .37 \\
\hline
\end{tabular}

the rate of disappearance of radiosulfate from plasma. Approximately 2.5 microcuries of radiosulfate per $\mathrm{Kg}$. of body weight were infused as previously described (3). Samples of blood were drawn from the femoral artery anaerobically into oiled, heparinized syringes at two, three, and four hours in one experiment, at two, four, six, and eight hours in two experiments. After sampling for measurement of hematocrit and concentrations of water and radiosulfate in whole blood, plasma was promptly separated by centrifugation under oil.

\section{c) Analytical methods}

Serum, plasma, and whole blood water concentrations were measured by weighing $1-\mathrm{ml}$. samples before and after drying at $105^{\circ} \mathrm{C}$. for 24 hours. Hematocrit and concentrations of radiosulfate, sodium, potassium, chloride, and hydrogen were measured by methods previously described $(3,12)$. Recovery of radiosulfate from whole blood equalled that from plasma (3). Concentrations of serum protein and "albumin" were measured by the biuret method (13), standardized by semi micro-Kjeldahl analysis of pooled sera. Sera were fractionated by the modification of Milne (14).

\section{Calculations}

Globulin concentrations have been calculated by difference from the concentrations of serum protein and "albumin." Concentrations of radiosulfate in the water of erythrocytes have been calculated by difference from measurements of water and radiosulfate concentrations in whole blood and plasma as described previously (3), with the exception that the hematocrit has been corrected for 4 per cent "trapped" plasma (15).

\section{RESULTS}

The ratios of concentration of radiosulfate in the water of serum to that in the dialysate are listed in Table I and average 0.95 for the five hu- 
man sera, 0.96 for the ten canine sera. The corresponding ratios for chloride are 0.99 for the human sera, 0.98 for the canine sera. The ratios of concentrations of sodium and potassium in the dialysate to those in the water of human and canine sera average 0.94 for each ion. The water content, $\mathrm{pH}$, protein concentration and albuminglobulin ratios are in or close to the normal range for human and canine plasma.

In Table II are listed the ratios of concentrations of radiosulfate in erythrocyte water to those in plasma water. In the three experiments this ratio ranged from 0.36 to 0.45 , did not change consistently with time and averaged 0.40 .

\section{DISCUSSION}

The observed ratios of concentrations of the monovalent ions, sodium, potassium, and chloride in serum water and dialysate are in close agreement with those observed by others (11). This agreement supports the validity of the experimental procedure for measuring the distribution of the sulfate ion across a semipermeable membrane under conditions approximating those existing at capillary membranes. As in the case of chloride (11) the observed ratios for radiosulfate $(0.95,0.96)$ differ from that $(0.90)$ calculated from the concentration of serum protein (4). Using the observed ratios $(0.95,0.96)$ in calculating the radiosulfate volumes of distribution in the whole body results in a volume approximately 5 per cent greater than that obtained using the theoretically derived ratio $(0.90)$.

The ratio of concentrations of radiosulfate in the water of erythrocytes and plasma $(0.40)$ is established within one hour and probably much sooner (8). This ratio remains essentially unchanged over a period of hours. Thus in approximating extracellular fluid volume by radiosulfate distribution correction for entry of radiosulfate into erythrocytes can be made from the measured hematocrit and measured or assumed plasma volume. Normally, with the hematocrit 0.45 , the plasma volume 4 per cent of body weight, the radiosulfate volume 23 per cent of body weight and the concentration of water in erythrocytes approximately 65 per cent, the extracellular fluid volume as measured by radiosulfate distribution will be 4 per cent larger when calculated without correction for radiosulfate within erythrocytes.
These two modifications of the previous calculations $(1,3)$ of the radiosulfate volume (Donnan factor of 0.96 , correction for radiosulfate entering erythrocytes) have opposite and approximately equal effects upon the calculated volume. Their application does not require modification of the statement that the volumes of distribution of radiosulfate and mannitol are equal in the dog.

The ratio of the concentrations of radiosulfate on each side of the erythrocyte membrane (0.40) is slightly lower than that calculated $(0.42)$ from the ratio of the chloride concentrations (approximately 0.65) (3) and the assumption that sulfate is passively distributed across the erythrocyte membrane of the dog in accordance with Donnan equilibrium. However this fairly close agreement between observed and theoretical ratios supports this assumption.

Change in hydrogen ion or water concentration in the erythrocyte will result in change in the ratio of radiosulfate concentrations across the erythrocyte membrane, just as such change will affect the ratio of chloride concentrations across the erythrocyte membrane (16). When, for example, carbon dioxide is lost from whole blood in sampling for measurement of radiosulfate concentration in plasma, hemoglobin in the form of ionized salt increases at the expense of that in the form of undissociated weak acid. In addition, the concentration of solute particles in the erythrocyte is reduced and water shifts from the erythrocyte to plasma. These new conditions require for membrane equilibrium a shift of sulfate from the erythrocyte to plasma, and a falsely high estimate of radiosulfate concentration in plasma results. The relative change in the ratio of concentrations of the divalent ion, radiosulfate, under such conditions is approximately twice the relative change in the ratio for the monovalent ion, chloride. However the error introduced in measuring plasma concentration, expressed as a per cent of the true value, is approximately the same for each ion, the effect of the greater change in the concentration ratio for the divalent ion being offset by the initial, smaller ratio of concentrations of this ion. An error of as much as 5 per cent may be readily introduced into the measurement of the plasma concentration of the anion (16).

An objection to the use of radiosulfate distribution in approximating extracellular fluid volume 
has been the apparent passage of sulfate through some cells (e.g., gastrointestinal and renal tubular epithelium) and that this anion is presumably distributed acros̀s the membranes of all cells in accordance with Donnan theory (17). In muscle the ratio of chloride concentrations across the cell membrane is much smaller than that in the case of erythrocytes, perhaps of the order of 0.02 . If such a distribution of chloride represents cells of the body generally, the ratio of intracellular to extracellular concentrations of the divalent ion, radiosulfate, would theoretically be of the order of 0.0004 . With a ratio of intracellular to extracellular concentrations of radiosulfate of this magnitude and with any reasonable change in this ratio as a result of experimental procedure, it would appear that the amount of inorganic radiosulfate within cells is much too low to affect significantly the calculated volume of distribution or to invalidate this application of radiosulfate distribution.

\section{SUM MARY}

The equilibrium concentration of radiosulfate in serum water has been measured as 0.95 (in five human sera) and 0.96 (in ten canine sera) the concentration in a dialysate separated from serum by a cellophane membrane. The ratio of the concentrations of radiosulfate in erythrocyte and plasma water remains approximately 0.40 for several hours after infusion of radiosulfate into the dog.

\section{REFERENCES}

1. Walser, M., Seldin, D. W., and Grollman, A., An evaluation of radiosulfate for the determination of the volume of extracellular fluid in man and dogs. J. Clin. Invest., 1953, 32, 299.

2. Walser, M., Seldin, D. W., and Grollman, A., Radiosulfate space of muscle. Am. J. Physiol., 1954, 176, 322.

3. Swan, R. C., Madisso, H., and Pitts, R. F., Measurement of extracellular fluid volume in nephrectomized dogs. J. Clin. Invest., 1954, 33, 1447.
4. Hastings, A. B., Salvesen, H. A., Sendroy, J., Jr., and Van Slyke, D. D., Studies of gas and electrolyte equilibria in the blood. IX. The distribution of electrolytes between transudates and serum. J. Gen. Physiol., 1927, 8, 701.

5. Donnan, F. G., The theory of membrane equilibria. Chem. Rev., 1924, 1, 73.

6. Bourdillon, J., and Lavietes, P. H., Observations on the fate of sodium sulfate injected intravenously in man. J. Clin. Invest., 1936, 15, 301.

7. Hald, P. M., Heinsen, A. J., and Peters, J. P., Effects of isotonic solutions and of sulfates and phosphates on the distribution of water and electrolytes in human blood. Am. J. Physiol., 1948, 152, 77.

8. Sheatz, G. C., and Wilde, W. S., Transcapillary exchange rate and volume of distribution of sulfate and sodium as indicated by $\mathrm{S}^{35} \mathrm{O}_{4}$, and $\mathrm{Na}^{24}$ in the rat. Am. J. Physiol., 1950, 162, 687.

9. Wilbrandt, W., Untersuchungen über langsamen Anionenaustausch durch die Erythrocytenmembran. Pflüger's Arch. f. d. ges. Physiol., 1942, 246, 291.

10. Schwietzer, C. H., and Passow, H., Kinetik und Gleichgewichte bei der langsamen Anion en permeabilität roter Blutkörperchen. Pflüger's Arch. f. d. ges. Physiol., 1953, 256, 419.

11. Manery, J. F., Water and electrolyte metabolism. Physiol. Rev., 1954, 34, 334.

12. Swan, R. C., and Pitts, R. F., Neutralization of infused acid by nephrectomized dogs. J. Clin. Invest., 1955, 34, 205.

13. Kingsley, G. R., The determination of serum total protein, albumin, and globulin by the biuret reaction. J. Biol. Chem., 1939, 131, 197.

14. Milne, J., Serum protein fractionation: A comparison of sodium sulfate precipitation and electrophoresis. J. Biol. Chem., 1947, 169, 595.

15. Gregersen, M. I., and Schiro, H., The behavior of the dye $\mathrm{T}-1824$ with respect to its absorption by red blood cells and its fate in blood undergoing coagulation. Am. J. Physiol., 1938, 121, 284.

16. Van Slyke, D. D., Wu, H., and McLean, F. C., Studies of gas and electrolyte equilibria in the blood. V. Factors controlling the electrolyte and water distribution in the blood. J. Biol. Chem., 1923, 56, 765.

17. Boyle, P. J., and Conway, E. J., Potassium accumulation in muscle and associated changes. J. Physiol., 1941, 100, 1. 